\title{
Lead intoxicated children in Kabwe, Zambia
}

Stephan Bose-O’Reilly ${ }^{\mathrm{a}, \mathrm{b}^{*}}$, John Yabe ${ }^{\mathrm{c}}$, Joseph Makumba ${ }^{\mathrm{d}}$, Paul Schutzmeier ${ }^{\mathrm{a}}$, Bret Ericson ${ }^{\mathrm{e}}$, Jack Caravanos ${ }^{\mathrm{e}, \mathrm{f}}$

a. Institute and Policlinic of Occupational, Social and Environmental Medicine, WHO Collaborating Centre for Occupational Health, University Hospital, LMU Munich, Ziemssenstr. 1, D-80336 Munich, Germany (stephan.boeseoreilly@med.unimuenchen.de)

b. Department of Public Health, Health Services Research and Health Technology Assessment, UMIT - University for Health Sciences, Medical Informatics and Technology, Hall i.T., Austria (stephan.boeseoreilly@umit.at)

c. University of Zambia, School of Veterinary Medicine, Lusaka, Zambia (john.yabe@unza.zm)

d. Misenge Environmental and Technical Services Ltd., ZCCM Investment Holdings Plc (ZCCM-IH), Kitwe, Zambia (makumbaj@mets.com.zm)

e. Pure Earth, New York, USA (bret@pureearth.org)

f. New York University of New York School of Public Health, New York, USA (Jack.Caravanos@sph.cuny.edu)

Reports from the field 
*Correspondence to:

Stephan Bose-O'Reilly, Global Environmental Health, Institute and Outpatient Clinic for Occupational, Social and Environmental Medicine, WHO Collaborating Centre for Occupational Health, University Hospital, LMU Munich, Ziemssenstr. 1, D-80336 Munich, Germany,

stephan.boeseoreilly@med.uni-muenchen.de

Fon: ++49-89-44005 7687, Fax ++49-89-44005 4444 


\begin{abstract}
Kabwe is a lead contaminated mining town in Zambia. Kabwe has extensive lead contaminated soil and children in Kabwe ingest and inhale high quantities of this toxic dust. The aim of this paper is to analyze the health impact of this exposure for children. Health data from three existing studies were re-analyzed. Over 95\% of children living in the most affected townships had high blood lead levels (BLLs) $>10 \mu \mathrm{g} / \mathrm{dL}$. Approximately $50 \%$ of those children had BLLs $\geq 45 \mu \mathrm{g} / \mathrm{dL}$. The existing data clearly establishes the presence of a severe environmental health crisis in Kabwe which warrants immediate attention.

Keywords: Lead poisoning; Children; Kabwe; Zambia
\end{abstract}

\title{
1. Introduction
}

Kabwe is the fourth biggest town and capital of the central province of Zambia. The town has a long history of mining, which operated for more than 90 years and produced large quantities of lead $(\mathrm{Pb})$ and zinc $(\mathrm{Zn})$ until closure in 1994.

Lead is a toxic substance and chronic exposure causes serious adverse health effects. The pathways of exposure are mainly ingestion of $\mathrm{Pb}$ contaminated soil and dust, but inhalation as a route of entry can also be significant. $\mathrm{Pb}$ can cause acute and chronic intoxication. High exposure can cause severe colic-like abdominal pains, neurological symptoms, seizures, encephalopathy and finally death .

Infants are at higher risk due to specific risk behaviors such as playing on bare soil, relevant hand to mouth activity and thus their oral uptake is greater compared with adults . While high blood $\mathrm{Pb}$ levels (BLLs) have been associated with extensive adverse effects, evidence of low BLLs causing serious negative health effects is extensive and conclusive. The negative effect 
of $\mathrm{Pb}$ exposure during pregnancy to the fetus and during early childhood on the regular development of the brain has enormous adverse implications .

The CDC Reference Level for $\mathrm{Pb}$ is $5 \mu \mathrm{g} \mathrm{Pb} / \mathrm{dL}$ blood (https://www.cdc.gov/nceh/lead/acclpp/blood_lead_levels.htm).. Between 5 and $44 \mu \mathrm{g} \mathrm{Pb/dL}$, actions to lower the body burden are recommended In the former "Kabwe lead poisoning management protocol" a $\mathrm{Pb}$ level of $20 \mu \mathrm{g} \mathrm{Pb} / \mathrm{dL}$ was considered as minimum level for individual follow up. The medical intervention level for children is $45 \mu \mathrm{g} \mathrm{Pb} / \mathrm{dL}$. Children with confirmed $\mathrm{Pb}$ encephalopathy need to be hospitalized and treated individually . Data from a large treatment survey in Nigeria indicates that oral chelation treatment with $C_{\text {Chemet }}{ }^{\circ}$ (succimer, DMSA) is both safe and effective. However, chelation therapy without environmental intervention may prove futile since re-exposure will likely occur.

\section{Environmental assessments}

Lead contaminated soils in Kabwe pose a serious environmental hazard. In 2003-2006, the "Copperbelt Environment Project" analyzed over 1,000 soil samples for $\mathrm{Pb}$ in various townships. The results showed, that the soil "over a substantial area is highly contaminated with the metal". "Median $\mathrm{Pb}$ concentrations of soil in townships in the vicinity of the mine inducing Kasanda $(3,008 \mathrm{mg} / \mathrm{kg})$, Makandanyama $(1,613 \mathrm{mg} / \mathrm{kg})$, Chowa $(1,233 \mathrm{mg} / \mathrm{kg})$, Mutwe Wansofu $(1,148 \mathrm{mg} / \mathrm{kg}$ ), Makululu $(870 \mathrm{mg} / \mathrm{kg})$ and Luangwa $(507 \mathrm{mg} / \mathrm{kg})$ were recorded. All exceeded levels generally regarded as acceptable by international authorities with respect to residential areas".

The most affected townships are immediately adjacent to the former Kabwe mining complex and homes downwind from the smelter and the tailings (see Figure 1).

Figure 1: Interpolated distribution of $\mathrm{Pb}$ in soil in the KSDS survey area based on district and township survey 
Regrettably, the situation appears to have changed little in recent years as shown from work done by Pure Earth (formerly Blacksmith Institute) in 2014. Data shows townships close to the mining area are still polluted with $\mathrm{Pb}$ levels in soil well above recommended levels for residential areas. Soil samples analyzed with an Innov-x Delta series X-ray fluorescence by Pure Earth found median soil concentrations of 3,212 mg/kg in Chowa, $6,162 \mathrm{mg} / \mathrm{kg}$ in Kasanda, and 2,286 mg/kg in Makululu . Citywide, surface soil $\mathrm{Pb}$ concentrations ranged from $139 \mathrm{mg} / \mathrm{kg}$ to $62,142 \mathrm{mg} / \mathrm{kg}$, with a geometric mean concentration of $1,470 \mathrm{mg} / \mathrm{kg}$. Of the 339 soil tests, 86 readings $(25.4 \%)$ were $>400 \mathrm{mg} / \mathrm{kg}$.

Figure 2: Concentrations of lead in surface soil

This overview of results shows that the $\mathrm{Pb}$ contamination of soils in Kabwe is serious with townships close to the mining area being highly contaminated. Lead is not the only contaminant of concern in Kabwe; the different assessments showed high levels of cadmium (Cd) and $\mathrm{Zn}$ in the surrounding mining area and adjacent townships .

The aim of this paper is to analyze whether the high lead exposure has a health impact on children in Kabwe.

\section{Health assessments}

Presently, there are three information sources on childhood BLLs in Kabwe; (1) data from the Copperbelt Environment Project; (2) data from projects of Pure Earth and (3) data from a University of Zambia with collaborators from Hokkaido University, Japan. A summary of BLL data is provided below.

\section{Copperbelt Environment Project}


Commissioned by the Government of the Republic of Zambia, funded by World Bank, the "Copperbelt Environment Project" performed the Kabwe Scoping and Design Study (KSDS) from 2003 to 2006. One of the aims of the KSDS was to update health and environment data for Kabwe. A specific aim was to reduce the geometric mean of BLLs substantially below $25 \mu \mathrm{g} / \mathrm{dL}$ for children in Kabwe. In the KSDS report, data from approximately 2,500 participants are presented. Children were recruited by study nurses from the different townships. BLLs were especially elevated in children 0-7 years old. Nearly all children were above the reference level of $5 \mu \mathrm{g} / \mathrm{dL}$ and in some highly exposed townships over $50 \%$ of the children had BLLs at which medical treatment was warranted (see table 1 .

The survey showed that the geometric mean BLLs in townships closer to the mining sites were higher. As shown in Table 1, the geometric mean BLLs of children aged 0-7 years in the surrounding townships were: Chowa $31.7 \mu \mathrm{g} / \mathrm{dL}$, Kasanda $32.8 \mu \mathrm{g} / \mathrm{dL}$, Makandanyama $38.2 \mu \mathrm{g} / \mathrm{dL}$ and Makululu $31.3 \mu \mathrm{g} / \mathrm{dL}$. The BLLs were in the range, where negative health effects are likely. Children aged 8-16 years and adults as well had increased BLLs, although lower than levels in children aged 0-7 years.

The KSDS report shows that a high percentage of inhabitants had BLLs above the "predetermined level of concern" of $25 \mu \mathrm{g} / \mathrm{dL}$. In detail it was extrapolated that 12,378 children aged 0-7, 7,919 children aged 8-16 and 3,973 adults would have BLLs $>25 \mu \mathrm{g} / \mathrm{dL}$ (see Table 1).

Misenge Environmental and Technical Services Ltd (METS) performed several blood sampling sessions in various townships. As is shown in supplement 1 , the geometric mean levels varied over time. There was no clear trend in the findings but differences in the geometric means among the townships were seen. The results showed that increased BLLs in Kabwe were widespread, especially in Makululu, Makandanyama and Kasanda where BLLs of children were constantly very high.

Recent data from METS was published in 2015 by the University of Zambia, Department of Public Health. In that study, BLLs in 1,166 children under five years of age from Makululu 
township were measured with a LeadCare II $^{\mathrm{TM}}$ portable blood instrument ((Magellan Diagnostics, Inc., N. Billerica, Massachusetts). The reported BLLs in Makululu were: :

- $99.4 \%$ of the children $>10 \mu \mathrm{g} / \mathrm{dL}$

- $73.2 \%$ of the children $>25 \mu \mathrm{g} / \mathrm{dL}$

- Geometric mean was $32.6 \mu \mathrm{g} / \mathrm{dL}$ (see Table 1)

Mbewe et al (2015) determined a statistically significant association between age and BLLs. The authors concluded that affected areas would "require an expansive and integrated program of $\mathrm{Pb}$ exposure prevention"; the program should be "implemented by government and co-operating partners" and that the program should also "take into account environmental management and disease surveillance".

\section{Pure Earth projects}

The previous findings were independently confirmed by BLL sampling performed in 2014 by Pure Earth . For the Pure Earth study, 196 children aged 2-8 years were selected from highly exposed townships. Their blood was tested with a LeadCare II ${ }^{\mathrm{TM}}$ analyzer. The mean BLL was $48.3 \mu \mathrm{g} / \mathrm{dL}$ and more than $50 \%$ of children would have needed medical treatment (see Table 1) . A substantial number (26.5\%) of childhood BLLs exceeded the $65 \mu \mathrm{g} / \mathrm{dL}$ upper detection limit of the LeadCare II ${ }^{\mathrm{TM}}$ instrument, which indicates that the poisoning was likely more severe than observed.

\section{University of Zambia / JICA projects}

Most recently a study in the three contaminated townships was conducted by the University of Zambia in collaboration with Hokkaido University. Children from the severely contaminated 
townships of Chowa, Kasanda and Makukulu were assessed. Blood lead levels were analyzed with ICP-MS analyzer (7700 series, Agilent technologies, Tokyo, Japan) in 246 children under the age of seven. The results showed that $100 \%$ of the sampled children had BLLs $>5 \mu \mathrm{g} / \mathrm{dL}$. Moreover, high BLLs of $\geq 65 \mu \mathrm{g} / \mathrm{dL}$ were recorded in: Chowa $18 \%$, Kasanda 57\% and Makululu 25\%. Eight children in Kasanda and two children in Makululu had very BLLs of $>150 \mu \mathrm{g} / \mathrm{dL}$, four children had extremely high BLLs of $\geq 300 \mu \mathrm{g} / \mathrm{dL}$ (for details see Table 1 and supplement 2).

Findings from Yabe et al. (2015) revealed extensive $\mathrm{Pb}$ poisoning in children in Kabwe and recommended chelation therapy, especially in children with BLL exceeding $\geq 45 \mu \mathrm{g} / \mathrm{dL}$. This was critical so as to curtail the pernicious health impact of $\mathrm{Pb}$ poisoning in children. Moreover, through an individualized follow-up plan of the affected children at their homes and regular health check-ups at local health centers, it was observed that the quality of life of the affected children could be improved. The authors also observed that early detection and intervention could be useful to minimize overt cases of $\mathrm{Pb}$ poisoning such as persistent seizures, mental retardation and death. This would require enhanced community awareness of $\mathrm{Pb}$ poisoning and urgent interventions in the affected areas, with the full participation of local townships and various stakeholders for the sustenance of remedial measures.

\section{Table 1: Lead levels by township and year in $\mu \mathrm{g} \mathrm{Pb/dL} \mathrm{blood}$}

Children with increased BLLs can develop clinical signs and symptoms of $\mathrm{Pb}$ intoxication. The data presented in this paper offers the most current and comprehensive reporting of BLLs in this highly contaminated city in Zambia. Three distinct groups of researchers have presented what appears to be continuing $\mathrm{Pb}$ poisoning on a major scale.

There is only one set of data set from UNZA / JICA containing some information about clinical findings from children in Kabwe. Data captured in questionnaires showed that 10 or more percent of children observed in 2012 had reported signs and symptoms, typical for chronic $\mathrm{Pb}$ intoxication, such as anemia, intermittent abdominal pains, limb pains, memory 
problems, headaches, weakness in hands and feet, and seizures or convulsions (unpublished data). The nurses employed by METS caring for 200 children with increased BLLs reported verbally that they observed similar symptoms in children. Nurses and health care workers from Makululu, Kasanda and Chowa health centers report that children have severe intermittent abdominal pains, seizures, are smaller and do not develop well compared with other children. These are first indicators that the children in Kabwe suffer from $\mathrm{Pb}$ poisoning severely.

\section{Discussion}

The existing data clearly establishes the severity of $\mathrm{Pb}$ exposure in Kabwe. Environmental data also support the observation that in certain housing areas of Kabwe, the recommended tolerable soil $\mathrm{Pb}$ level of $400 \mathrm{mg} / \mathrm{kg}$ is clearly exceeded (see Figure 1 and Figure 2). The soil levels measured by Pure Earth 2014 are in general higher compared to those reported by KSDS in 2006. We suspect this results from enhanced granularity now available with a portable XRF (rather than an actual increase in concentrations).

Nearly all children in the townships close to the former mining area had BLLs $\geq 20 \mu \mathrm{g} / \mathrm{dL}$, which is a value where urgent action is demanded to decrease the exposure immediately according to the KSDS study protocol. Since soil is the major pathway of exposure in Kabwe the most important task is to decrease exposure for all children by immediate and appropriate remediation.

In the most affected townships, approximately $50 \%$ of the children have BLLs $\geq 45 \mu \mathrm{g} / \mathrm{dL}$, which is the threshold value above which medical antidote treatment is recommended. The former interventions of the KSDS project did not show any long term effect in reducing the environmental pollution nor the BLLs of children. In Makululu, Makandanyama and Kasanda, BLLs of children are even higher compared with other townships. Large proportions of children are not only highly exposed, but have high to extremely high levels of $\mathrm{Pb}$ in their bodies. From the KSDS survey it can be estimated that approximately $60 \%$ of children with 
BLLs $\geq 25 \mu \mathrm{g} / \mathrm{dL}$ might have BLLs of levels $\geq 45 \mu \mathrm{g} / \mathrm{dL}$. According to threshold levels and international recommendation, the exposure has to be considerably reduced and the children need medical treatment. Children with BLLs $\geq 45 \mu \mathrm{g} / \mathrm{dL}$ should receive medical treatment . However medical treatment without environmental and educational intervention will not be enough to sustain a safe and healthy population.

\section{Acknowledgement}

Funding by World Bank (Environment remediation and improvement project (P154683) is appreciated (SB). Funding by Pure Earth is gratefully acknowledged (JC). Funding from the European Union's Seventh Programme for research, technological development and demonstration under grant agreement No 603946 (Health and Environment-wide Associations based on Large population Surveys, HEALS) is acknowledged (SB). 


\section{References}

